\title{
Modernismo brasileiro: muito além da Semana de Arte Moderna de 1922
}

Brazilian Modernism: beyond the Modern Art Week of 1922

José Lúcio da Silva Menezes

Mestre em História Social (PUC-SP); Professor do curso de História (Uninove).

São Paulo, SP - Brasil.

luciomenezes21@gmail.com

\section{Resumo}

Este artigo tem por objetivo discutir a hegemonia paulistana como marco emblemático da Semana de Arte Moderna de 1922 que a consagrou, ao longo do século XX, como o grande referencial de renovação das artes e do pensamento brasileiro. Propõe também a discutição das fronteiras territoriais da produção do Modernismo a partir da interpretação de autores, sobretudo cariocas, que se colocaram como críticos da hegemonia dos intelectuais paulistas da Semana de 1922.

Palavras-chave: Historiografia. Modernismo. Modernização. Semana de Arte Moderna de 1922.

\begin{abstract}
In this paper is discussed the hegemony of Sao Paulo as an emblematic landmark of the Modern Art Week of 1922 that enshrined itself, during the twentieth century, as the major reference on the renewal of the Brazilian arts and thought. Thus, it is also proposed to discuss the territorial boundaries of the Modernism production, looking at some authors' interpretation, mainly those that are from Rio de Janeiro, who set themselves up as critics of the Sao Paulo intellectual hegemony during the Week of 1922.
\end{abstract}

Key words: Historiography. Modern Art Week of 1922. Modernism. Modernization. 


\section{Introdução}

A Semana de Arte Moderna de 1922 consagrou-se ao longo do século XX como o grande referencial da renovação das artes e do pensamento brasileiro. São Paulo, por conseguinte, ficou, no imaginário nacional, como o local privilegiado daquele processo de renovação. A cidade sagrou-se símbolo do movimento liderado por Mário de Andrade e Oswald de Andrade e outras dezenas de artistas provenientes das mais diferentes áreas. Pouco se fala, desde então, das produções modernistas em outros espaços do Brasil. A proposta deste artigo é discutir as fronteiras territoriais da produção do Modernismo a partir da interpretação de autores, sobretudo cariocas, que se colocaram como críticos da hegemonia paulistana em relação à Semana.

A Semana de Arte Moderna de 1922 foi um evento que tinha como princípio promover rupturas no interior das artes plásticas no Brasil, nesse passo rompendo com o passado acanhado das tradições e fazendo o país ingressar na modernidade. São artistas e intelectuais que querem descobrir o Brasil profundo e desejam repensar a nossa identidade coletiva. Foi um movimento que buscou uma cisão com o passado de herança portuguesa. O Brasil tinha que entrar na Nova Ordem Mundial (NOM) pela porta da frente da modernidade. Para o professor Antonio Candido (2010, p. 125),

A Semana da Arte Moderna [...] foi realmente o catalisador da nova literatura, coordenando, graças ao seu dinamismo e à ousadia de alguns protagonistas, as tendências mais vivas e capazes de renovação, na poesia, no ensaio, na música, nas artes plásticas. Integram o movimento alguns escritores intimistas como Manuel Bandeira, Guilherme de Almeida; outros, mais conservadores como Ronald de Carvalho, Menotti Del Picchia, Cassiano Ricardo; e alguns novos que estrearam com livre e por vezes desbragada fantasia: Mario de Andrade, Oswald de Andrade na poesia e na ficção; Sérgio Milliet, Sérgio Buarque de Hollanda, Prudente de Moraes Neto, no ensaio.

Assim, esses intelectuais de diferentes matizes, uns mais conservadores e outros de "desbragada fantasia", recolheram de dentro da própria cultura produ- 
zida pelos diferentes segmentos de classe a "essência" da alma brasileira. Essa "essência" estaria com suas raízes fincadas na cultura popular.

No entanto, esse processo não esteve restrito ao movimento ocorrido na cidade de São Paulo. Encontramos essa lufada de novos ares em Recife, Belo Horizonte $^{1}$, Rio de Janeiro e na pequena Cataguases, no interior de Minas Gerais. Ficaremos circunscritos, preferencialmente, às diferenças substantivas entre Rio, São Paulo e Recife, dados os limites de um artigo. Apontar as diferenças no interior deste movimento, que se deu em escala nacional, pode ser um caminho para compreendermos a hegemonia paulistana como o palco por excelência da modernidade brasileira. Foram movimentos que expressavam as muitas possibilidades de repensar o país. Diferentes na forma, no entanto, tinham em comum a ânsia por modernizar o país.

\section{Mudanças na base social}

A década da Semana de Arte Moderna viu o país passar por profundas transformações. A industrialização consolidou-se, sem dúvida, nesse período, embora ainda tardia e incipiente para transformar a profunda dependência e subordinação de uma república recém-proclamada, que ainda vivia sob os auspícios das elites mais conservadoras e vinculadas ao agrarismo dominante.

A Primeira República é um tempo de consolidação do parque industrial brasileiro, processo que teve início ainda no século XIX, de forma embrionária e tímida, e que teria desenvolvimento mais amplo no limiar do século XX. Foi este fenômeno que provocou mudanças profundas na ordem social vigente. Os diferentes grupos constitutivos do tecido social viveram conflitos intensos na arena pública brasileira. O enfrentamento com as velhas oligarquias era inevitável, dado o descompasso entre as transformações na base social e a manutenção do estilo de poder que vigorava desde o século anterior à Republica.

No decorrer do processo de mudança política, os cargos rendosos e decisórios - antigos e novos - passaram rapidamente para as mãos desses grupos recém-chegados à distinção social, premiados com as ondas sucessivas e fartas de "nomeações", "indenizações", "garantias", "subvenções", "favores", "privilégios", e "proteções" 
do novo governo. O revezamento das elites foi acompanhado pela elevação do novo modelo do burguês argentário como o padrão vigente do prestígio social. Mesmo os gentis-homens remanescentes do Império, aderindo à nova regra, "curvam-se e fazem corte ao burguês plutocrata”. Era a consagração olímpica do arrivismo agressivo sob o pretexto da democracia e o triunfo da corrupção destemperada em nome da igualdade de oportunidades. (SEVCENKO, 2009, p. 38)

O desenho do poder republicano elaborado pelo professor Nicolau Sevcenko traduz, com precisão, a natureza do poder das elites brasileiras do período histórico em tela. A mesma arguta observação das características de nossas elites encontrou respaldo nas interpretações de José Murilo de Carvalho (1998, ps. 95-96):

O espírito de especulação, de enriquecimento pessoal a todo custo, denunciado amplamente na imprensa, na tribuna, nos romances, dava ao novo regime uma marca incompatível com a virtude republicana. Em tais circunstâncias, não se podia nem mesmo falar na definição utilitarista do interesse público como sendo a soma dos interesses individuais. Simplesmente não havia preocupação com o público. Predominava a mentalidade predatória, o espírito do capitalismo sem a ética protestante.

Tal postura confronta-se com os novos segmentos sociais que emergem com a industrialização, advindos das fortes correntes migratórias, além de milhares de pessoas expulsas dos campos com a extinção da escravidão. A crescente urbanização gera novos extratos sociais, nos quais se destaca uma frágil classe média², assim como um operariado com vigor suficiente para enfrentar segmentos dominantes cuja mentalidade sequer reconhecia o trabalho como atividade remunerada. Miséria e exclusão profundas configuram lutas que indicam também o enfrentamento desses segmentos sociais com as velhas práticas políticas das oligarquias que ainda monopolizavam o poder no Brasil, do qual são exemplos a Revolta de Canudos, a da Chibata e a da Vacina.

São tais elites que os demais setores da sociedade brasileira, notadamente a classe operária, tiveram que enfrentar para conquistar alguns e parcos direitos 
políticos. Um confronto com um setor que nunca conseguiu perceber o conjunto da população como portadora de direitos, somente sujeita à exploração, sem uma devida ética a nortear suas ações na construção do capitalismo brasileiro. Um grupo que se pretende moderno, porém, apenas o é nas aparências. Sua essência era ainda bastante conservadora, visto que as ações dos extratos sociais dominantes na realização de seu papel social de solucionar os problemas vigentes na sociedade ficam aquém das possibilidades dadas, o que impede o pleno desenvolvimento das forças sociais. Essa particularidade das práticas dos setores que detêm o poder econômico ficou consagrada como "modernização conservadora", a qual seria a marca das elites brasileiras. Por conseguinte, o que caracterizaria essa forma particular de desenvolvimento seria

[...] a recusa a mudanças fundamentais na propriedade da terra. Os grandes proprietários manteriam, destarte, controle também sobre a força de trabalho rural, que não seria capaz, portanto, de se libertar de relações de subordinação pessoal e de extração do "excedente" econômico por meios mais diretos. [...] Na modernização conservadora, as tradicionais elites agrárias forçaram uma burguesia relutante e avessa aos processos de democratização a um compromisso: a modernização fazia-se sob a liderança e levando muito em conta os interesses dos proprietários agrários, conformando-se uma "subjetividade coletiva" centrada em um bloco transformista, cauteloso e autoritário em suas perspectivas e estratégias. (DOMINGUES, 2002, p. 460-461)

Ainda no que diz respeito às particularidades desses grupos dominantes em formações sociais atrasadas como a do Brasil do início do século XX, verificase um comportamento geral de classe tímido e apequenado diante das tarefas históricas que lhes caberia para o desenvolvimento de suas economias. Era uma classe que já nascera frágil e débil.

Ela luta, simultaneamente, por sua sobrevivência e pela sobrevivência do capitalismo. Isso introduz um elemento político em seus comportamentos de classe que não é típico do capitalismo especialmente nas fases de maturação econômica, sociocultural e 
política da dominação burguesa na Europa e nos Estados Unidos. Essa variação, puramente histórica, é, no entanto, central para que se entenda o crescente divórcio que se dá entre a ideologia e a utopia burguesas e a realidade criada pela dominação burguesa. Entre a ruína final e o enrijecimento, essas burguesias não têm muita escolha propriamente dita (isto é "racional", "inteligente" e "deliberada"). O idealismo burguês precisa ser posto de lado, com seus compromissos mais ou menos fortes com qualquer reformismo autêntico, com qualquer liberalismo radical, com qualquer nacionalismo democrático-burguês mais ou menos congruente. (FERNANDES, 1976, p. 296)

As referências às posturas conservadoras, neste trabalho, dizem respeito a essa forma de ser social de determinados grupos. Tratava-se de setores que foram construídos no interior de um processo histórico que configura, de modo específico, a visão de mundo de tais extratos sociais. Afasta-se, portanto, qualquer margem para entender este conceito como um julgamento moral ou de valor sobre qualquer sujeito social aqui arrolado.

A formação da classe operária, assim como a das classes médias urbanas, também obedece à lógica da industrialização crescente. Esse grupo vem das mais distintas origens: são brasileiros de outros estados que migram para São Paulo, em geral, provenientes do meio rural; são filhos dos ex-escravos que disputam um espaço no universo do trabalho; são imigrantes estrangeiros, sobretudo italianos, que acorrem à cidade. Essa base heterogênea compõe este setor de classe. Assim,

Falar de uma classe operária "branca”, composta em sua maioria de imigrantes europeus, é sem duvida uma avaliação globalmente correta para os estados de São Paulo e do Sul, mas desconsidera o peso do operariado "nacional", com significativa participação de negros e mulatos no restante do país. (BATALHA, 2003, p. 164)

No interior desse grupo, ideologias socialistas, anarquistas e comunistas tiveram seu florescer na construção das organizações dos trabalhadores. Já nos primórdios da industrialização, os enfrentamentos de classe colocaram em cena as diferenças entre as elites arrivistas e os interesses do mundo fabril. O diálogo 
não será dos mais democráticos. As reivindicações foram tratadas como caso de polícia. Diante da movimentação dos trabalhadores que provocam alterações na ordem social, as elites, incapazes de lidar com seus antagonistas, entendem-nos apenas como um grupo próximo à criminalidade comum. Não são portadoras de diálogos políticos para resolver os interesses conflitantes.

Os anos de 1918, 1919, 1920 registrariam ainda o desencadear de greves e da reação policial, publicamente justificada ao reduzir o movimento à ação de bandidos, fazendo das prisões e da deportação o destino comum de muitos anarquistas. (MOURA, 1997, p. 48)

"Bandidos" ou "ameaça à ordem pública" são as representações construídas acerca dos trabalhadores com visibilidade nos espaços públicos. Rodrigues Alves, ex-presidente do país, em pronunciamento na Câmara dos Deputados, em 1917, revela o pensamento das elites sobre os transtornos causados a uma ordem social hierarquizada que não comporta movimentos desta natureza.

Os últimos acontecimentos, que perturbaram séria e profundamente a nossa vida, sob todos os seus aspectos, vieram demonstrar, de modo incontestável, que a força pública que possuímos é de todo insuficiente, demasiado pequena para as necessidades de um policiamento regular e eficaz. Não fora a abnegação, o desprendimento, a correção, nunca desmentida, com que os nossos soldados cumprem os seus deveres, por certo com maiores e mais sérios embaraços lutaria o governo para manter e assegurar a tranquilidade pública. (Anais da Câmara dos Deputados do Estado de São Paulo, 1917, p. 119, apud MOURA, 1997, p. 46)

Apesar de tratados como "bandidos" pelas forças da ordem, a agitação no interior das classes populares não arrefeceu. Os embates intensificaram-se na busca de uma sociedade pautada por relações sociais mais justas e equânimes. Em 25 de Março de 1922 foi fundado o Partido Comunista Brasileiro (PCB), uma organização partidária pautada nos objetivos específicos da classe operária cuja fundação sinaliza para o crescente movimento de classes que estava, então, em plena disputa na cena pública e que adentraria os anos de 1920. 
Esse é o quadro social do Brasil na década de 1920. Foi o cenário, contraditório e tensionado, que emoldurou as reflexões dos modernistas brasileiros dos meados do século XX. As mudanças na base social vão impulsionar os anseios de modernização propostos pelos diferentes projetos modernistas do período.

\section{Modernismo brasileiro e sua pluralidade}

A modernidade é paulistana. São Paulo ganhou esse status porque foi em seu território que se concentrou o desenvolvimento propiciado pelo processo de industrialização. Em que pese ela ter sido durante muito tempo uma cidade acanhada e provinciana, no início do século XX passa por considerável transformação em sua configuração urbana e social. O Rio de Janeiro, por outro lado, era a capital federal desde o período colonial, situação que oferecia ao estado uma condição privilegiada no cenário nacional, haja vista que era o centro da vida cultural do país. Para lá acorreram artistas e intelectuais das mais diferentes partes do país. No entanto, foi São Paulo que ficou com o título de capital do modernismo brasileiro. Ainda assim, segundo os diferentes autores que trataremos neste artigo, essa é uma imagem redutora de um movimento complexo que transcende a dimensão paulista de sua concretude.

Esse duelo já estava instalado entre seus participantes mais ilustres. Mário de Andrade, figura símbolo da Semana de 22, em conferência no auditório da Biblioteca do Itamaraty em 30 de abril de 1942, que tinha como tema "O Movimento Modernista", não esconde suas diferenças com a cidade do Rio de Janeiro. Nesse mesmo colóquio, o autor ressalta as diferenças de classe que estavam por trás da criação e execução do Modernismo brasileiro. Suas palavras expõem as cisões no interior do próprio projeto modernista. Ele localiza em Paulo Prado, membro da aristocracia cafeeira paulista, o mentor principal da realização da Semana:

Além de audaciosa, dispendiosíssima. E o fautor verdadeiro da Semana de Arte Moderna foi Paulo Prado. E só mesmo uma figura como ele e uma cidade grande, mas provinciana como São Paulo, poderiam fazer o movimento modernista e objetivá-lo na semana. (Apud BERRIEL, 2000, p. 80-81) 
No evento, o autor dedica-se a explicitar por que o Rio não poderia sediar a Semana de Arte Moderna. A "Corte", como ele se referia à capital federal, abrigava todas as instituições que eles combatiam, sobretudo a Academia Brasileira de Letras, como também a Academia Nacional de Belas Artes. Esses espaços produziam, segundo ele, tudo aquilo que deveria ser ultrapassado. $\mathrm{O}$ Modernismo é, portanto, para nosso autor, a ruptura também com as produções cariocas associadas à continuidade de um Brasil que se transforma. Essa dimensão de classe em Mário de Andrade e sua indisposição com o Rio de Janeiro é avaliada por Carlos Eduardo Ornelas Berriel. Para ele, o discurso do modernista paulista

Principia com a oposição entre Rio e São Paulo, justificando a incidência da segunda como sede da Semana. Enquanto o Rio era porto marítimo, capital do país e internacionalista, São Paulo tem uma história de isolamento geográfico e provincianismo; o Rio possuía uma burguesia endinheirada com um espírito coerente com esta condição - isto é, covarde; São Paulo possuía uma verdadeira aristocracia que, além do mais, era casada com a modernidade industrial e com o comércio mundial. Mais técnica e mais atualidade. O Rio possuía uma instituição cultural - as academias - comprometida com a continuidade, enquanto o Modernismo era justamente uma ruptura com este tipo de inteligência. (BERRIEL, 2000, p. 84)

Nicolau Sevcenko também ressalta o caráter aristocrático dos sujeitos da Semana quando traça o estilo de vida e o ambiente em que circulava um dos principais mentores daquele evento na capital paulista, Paulo Prado:

O retorno a São Paulo, em particular de Paulo Prado, premido pela irrupção da Guerra, após uma longa itinerância de diletante pela Europa, por designação de sua própria família, iria mudar em definitivo o cenário político e cultural vigente. Era em sua casa e na de Olívia Guedes Penteado - igualmente recém-chegada da Europa pelo início da Guerra e viúva desde 1915 do grande fazendeiro de café Ignácio Penteado - que 
os jovens interessados em 'artes modernas' encontravam as últimas revistas, livros, informações, obras, chegados da Europa, e as portas abertas. (SEVCENKO, 2009, p. 235)

Assim, foi-se construindo paulatinamente o divórcio entre Rio e São Paulo, a ponto de ocultar as manifestações de natureza modernista na capital do país. A ênfase nas diferenças das classes que organizavam a vida social nas duas cidades é de suma importância para compreendermos esse divórcio.

[.. .] há uma substancial diferença entre as classes sociais e a relação destas com o óbice da ruptura: a aristocracia - o Modernismo era aristocrático - tem estatuto mental e lastro histórico para entrar numa aventura em que as reputações ficam questionadas; já a burguesia guarda-se ciosa de sua aparência, e aposta no que já deu certo. (BERRIEL, 2000, p. 84)

Nesse debate, o que podemos observar é que a querela de Mário de Andrade dá-se no interior de um mesmo grupo: o setor dominante, seja econômico ou intelectual, tanto de São Paulo quanto do Rio de Janeiro. Ou melhor, uma luta contra as academias instaladas na "Corte" e suas propostas de continuísmo em oposição a um país que teve suas bases sociais revolucionadas em curto espaço de tempo: as primeiras décadas do século XX. Nesse sentido, as contendas de Mário de Andrade ganham legitimidade incontestável. No entanto, cabe perguntar: o Modernismo no Rio de Janeiro ou em outras regiões do país pode ter se desenrolado em outros espaços que não as tradicionais academias, severamente atacadas por Mário de Andrade?

O Rio de Janeiro como Capital Federal, ou a "Corte", nas palavras de Mário de Andrade, tornou-se um centro para onde aportaram brasileiros vindos de toda parte do país, sobretudo ex-escravos que lá também buscaram abrigo. Era uma cidade efervescente, sintonizada com o que há de mais moderno: o cinematógrafo, o fonógrafo, a fotografia e as transformações na imprensa (SUSSEKIND, 2006). Olavo Bilac - poeta e cronista - expressou seu inconformismo com esse mundo em transformação, legando um depoimento de como era vivida essa modernidade nas ruas da capital com a chegada dos equipamentos de gravação de áudio: os discos da Casa Edson. 
De cada porta irrompe a voz esganiçada de u'a máquina falante ou cantante; são urros, gemidos, garganteios frenéticos, imprecações, ganidos, carcarejos [sic], miados, latidos, mugidos, arrulhos, guinchos, berros, grunidos! E a mísera Rua do Ouvidor parece uma galeria do inferno, cheia de condenados e réprobos, prisioneiros em caldeiras de pez fervente, vociferando maldições e pedindo misericórdia. (Apud SÜSSEKIND, 2006, p. 20)

Esse membro fundador da Academia Brasileira de Letras, instituição combatida pelo Modernismo de São Paulo, mostra-se em desconforto com a modernidade trazida pelo desenvolvimento das forças produtivas do capital que se populariza pelas ruas do Rio de Janeiro. É justamente nesse espaço vivo e dinâmico, as ruas da "Corte", que Monica Pimenta Velloso (1996) buscou os sinais da Modernidade carioca em oposição ao similar paulista de viés aristocrático. Num mesmo sentido, Ângela de Castro Gomes (1999) vislumbra uma intelectualidade marginal dentro da própria sociedade carioca. Artistas, boêmios, humoristas que não tinham espaço nas academias e nas altas rodas sociais são objeto das autoras para questionarem os referenciais do modernismo brasileiro que têm a Semana de Arte Moderna em São Paulo como o único marco daquele momento da história do Brasil. Momento de repensar a identidade nacional em um ano emblemático: 1922, centenário da Independência.

O Rio tornou-se uma cidade plena de conflitos e tensões no alvorecer da República. Houve uma espécie de continuidade na gestão da vida pública em relação ao período monárquico: a manutenção de uma ordem social excludente. Essas práticas atingiram, sobretudo, a população negra, antes escrava, agora cidadã de segunda classe na agenda das elites econômicas e políticas. Um símbolo desses mundos em desencontro talvez seja a Revolta da Vacina, dentre outros que poderíamos citar. Apesar desses mundos, setor popular e elite, não se entenderem muito bem, os diferentes grupos vão construindo processos de sociabilidade cada um a seu modo, o que levaria a uma produção de capital simbólico muito peculiar.

Na capital, um mundo paralelo às academias desenvolveu-se: os humoristas que registravam sua visão sobre o Brasil em diferentes periódicos, e que eram, de certa forma, marginais às altas rodas sociais. Foi precisamente nesse universo que Monica Pimenta Velloso buscou novas leituras sobre o Modernismo brasileiro. Fazer do humor um objeto de análise permite colocar em cheque a visão de Paulo 
Prado sobre a tristeza atávica da nacionalidade brasileira, uma vez que os intelectuais da revista $D$. Quixote não admitiam tal marca de nossa personalidade coletiva.

Nas revistas e jornais cariocas ficou claro o enfoque satíricohumorístico no tratamento dos acontecimentos cotidianos que mobilizavam a cidade. Nos escritos de Lima Barreto, nas caricaturas da Revisa da Semana, da D. Quixote e do Jornal do Brasil, encontrei uma reflexão fortemente marcada por esta tônica. [...] $\mathrm{O}$ fato me instigou a repensar a modernidade carioca, tomando outro caminho para compreender o modernismo fora do paradigma paulista em que forçosamente acabou se convertendo o movimento de 1922. Enfim, a questão, um tanto quanto desafiante, era repensar o próprio sentido de moderno. Entendê-lo na dinâmica acidentada do cotidiano, através de uma linguagem de forte apelo visual. (VELLOSO, 1996, p. 17)

Assim, cabe uma questão: as querelas de Mário de Andrade não são com os agentes do modernismo carioca e, sim, com as academias que também não reconheciam esses intelectuais. O debate pode estar fora do eixo, uma vez que a autora localiza a modernidade carioca em espaços marginais, ao contrário da marca aristocrática do movimento em São Paulo. Destarte, todo o processo de modernização do Rio de Janeiro, expresso nas reformas urbanas de Pereira Passos, não contemplou a incorporação das camadas populares nem dos intelectuais. Estes acabaram marginais à modernidade vinda de cima. Por essa razão, eles se debruçaram sobre o mundo das ruas na busca de outros referenciais de sociabilidade como contraponto às altas rodas sociais da "Corte", que também os rejeitava. (VELLOSO, 1996)

Dessa forma, começam a se desenhar as diferenças entre Rio e São Paulo na condução e percepção do Modernismo. Enquanto na capital paulista os intelectuais, em torno da aristocracia, constituíram-se em um movimento organizado, na "Corte" houve exatamente o oposto, uma recusa em formar um grupo coeso.

Os intelectuais cariocas que dão ênfase às ruas enquanto canal de sociabilidade, e mesmo de aprendizagem, refutam ao mesmo 
tempo a ideia de um movimento literário organizado. É provável que essa negação tenha a ver com uma imagem indesejada da literatura, associada à vida oficial e burocrática. No imaginário desses intelectuais, a ideia de um projeto remetia à de sua institucionalização, o que significava perda de originalidade e, sobretudo, comprometimento. (VELLOSO, 1996, p. 29)

Rio e São Paulo construíram-se sobre algumas imagens que podem até ser redutoras ou mesmo estereotipadas, mas que, de qualquer forma, nortearam o pensamento de vários intelectuais. São Paulo é por excelência o locus do trabalho sério, terra da produção industrial e da eficiência; o Rio, sede da burocracia federal, não muito afeito ao trabalho árduo, era terra da boêmia onde nada se leva muito a sério.

São igualmente conhecidas as interpretações que, mais recentemente, têm procurado tratar das características da cidade do Rio de Janeiro, o que teria implicações sólidas no tipo de intelectual e de produção cultural nela desenvolvida. De forma esquemática, o que nelas se ressaltou e ficou assentado foi o fato de a condição de 'capitalidade' ter gerado uma cidade dominada pela forte presença do Estado e das atividades de serviços (comércio e burocracia pública), o que se confrontaria com o caso da cidade de São Paulo, organizada pela produção (industrial com destaque) e pelo ethos, ao mesmo tempo competitivo e articulador do mercado. (GOMES, 1999, p. 21-22)

É também nessas especificidades da cidade do Rio de Janeiro que se engendrou um tipo particular de intelectual que tanto Castro Gomes quanto Velloso buscaram entender como o diferencial do Modernismo paulista e carioca. Ambas apontam para a posição marginal desses sujeitos na capital: sejam os humoristas da revista D. Quixote, sejam os intelectuais em torno da revista Festa e da Sociedade Felipe d'Oliveira. Uma condição de inadequação ao instituído que estaria em oposição ao intelectual paulista plenamente aceito e reconhecido pela aristocracia cafeeira. Aliás, parte deles oriundos desta mesma aristocracia. 
Em relação ao intelectual carioca, o perfil construído é o de um produtor de bens simbólicos que está marcado por uma dupla e contraditória inscrição social. De um lado, ele possuiria um estreito vínculo com o Estado, pois seria com muita frequência um funcionário público, o que o impregnaria de um misto de dependência, atração e desprezo por seu "patrão". De outro, por não conseguir um grande reconhecimento social ou por não conseguir ascender às altas esferas do poder político, integrando e influenciando suas instituições de maneira profunda, acabaria por eleger a "rua" como seu locus de sociabilidade por excelência, tendo na vida boêmia e na convivência com a população marginal um de seus traços definidores. (GOMES, 1999, p. 24)

O intelectual carioca, portanto, encontrava-se na marginalidade em relação às instituições oficiais, como a Academia Brasileira de Letras, e também em relação às elites políticas e econômicas. Essa condição empurrou-o para os braços das camadas populares. É um grupo que não ensejou para si o papel de timoneiro do Modernismo nacional, mas eram tão desejosos e portadores dessa nova mentalidade que se instaurava no país quanto os modernistas em São Paulo.

Em um sentido diverso do carioca temos também em Recife um movimento modernista que existiu no entorno do regionalismo que, por sua vez, não era muito bem-visto em São Paulo. Afinal, na capital paulista, os olhos estavam direcionados para o futuro. O Brasil tinha que entrar na Nova Ordem Mundial e o olhar regionalista não propiciaria esta entrada. Por que então esta diferença com a Pauliceia desvairada?

O desenvolvimento do Brasil ocorreu de forma desigual em suas diferentes regiões. Durante os séculos iniciais de nossa formação, a região mais viva da economia estava concentrada no Nordeste, enquanto São Paulo era uma região de menor importância para a Coroa portuguesa que era, então, a Metrópole que controlava o território. Esse período deixou marcas riquíssimas na cultura barroca do Nordeste. Tal quadro se alterou radicalmente a partir do século XIX, quando o Nordeste entrou em decadência e assistiu à ascensão de São Paulo a novo polo dinâmico da economia do país. Este breve quadro, aqui traçado, é de grande valia para entendermos as diferenças dos projeto modernista paulista e o desenhado na cidade de Recife. 
Se, como observamos, no Rio de Janeiro localizamos os modernistas em uma condição marginal, em Recife há o deslocamento na natureza dos produtores. Lá o projeto não foi liderado por artistas: o grande mentor foi Gilberto Freyre, um sociólogo. Ele foi o responsável por arejar o pensamento na capital pernambucana. Face ao quadro desenhado anteriormente, Freyre voltou seus olhos para o passado de glória do Nordeste em oposição ao futurismo do modernismo paulista antenado com as vanguardas europeias. A terra de Freyre parou no tempo; estagnou-se numa sociedade agrária e patriarcal. Assim,

Para o intelectual nordestino, em busca de afirmação no plano nacional, não se tratava de encontrar linguagens artísticas revolucionárias para exprimir um mundo em acelerada transformação, mas de procurar apoiar-se na riqueza das tradições culturais e artísticas locais, para fazer de sua revalorização sua bandeira de luta. Assim, não deve causar surpresa o fato de, nos anos 20, os escritores da região retomarem o caminho do regionalismo, [...]. (ALMEIDA, 2003, p. 321)

Em um mesmo sentido de compreender as diferenças entre São Paulo e Recife, apontando um para a estética como matéria prima, e outro para a história e a tradição como fermento, Antonio Dimas (2003, p. 40) observa que,

Num primeiro momento, pelo menos, São Paulo tinha em mira a estética; Pernambuco, a história. Estética e história eram, pois, os alicerces dos dois movimentos, e o que ocorreu depois, em torno de ambos, foram desdobramentos de enorme qualidade, sem dúvida, mas que se seguiram no rasto do primeiro.

O que podemos observar é que tanto Mário de Andrade quanto Gilberto Freyre, em que pese o conservadorismo do segundo, tinham ânsia por modernizar o país. Renovar as artes e o pensamento, mesmo que com olhos postos em direções divergentes. Um em direção a um futuro pleno de possibilidades e o outro a um passado com uma tradição riquíssima que poderia revalorizar um presente adormecido pela decadência econômica. 
[...] no fundo, modernismo e regionalismo são apenas faces diferentes de um mesmo processo de luta pelo aprofundamento da consciência nacional, na arte como na cultura: é natural que, em cada momento histórico e em cada latitude, o sol ilumine, com luz diversa, cada uma dessas múltiplas faces. (ALMEIDA, 2003, p. 325)

O Modernismo brasileiro, em suas diferentes configurações, buscou compreender o sentido da brasilidade naquele ano emblemático do centenário de nossa independência. Logrou colocar a cultura popular em outro patamar de reconhecimento, diferente dos momentos anteriores em que também se buscou pensar a nacionalidade brasileira, sobretudo no pós-independência. São traços em comum que podemos identificar nos "movimentos" de renovação encarnados no Modernismo. Desde os mais conservadores até os mais progressistas, todos queriam as artes e o pensamento em sintonia com as mudanças que ocorreram na base social e política do país.

No entanto, em face de múltiplos projetos modernistas, observamos que apenas o de São Paulo ficou para a história, quase como o único projeto. Algumas considerações podemos fazer sobre essa definição histórica. As diferenças de classe e de postura parecem ser um indicador que apontam para a permanência, no tempo, do movimento paulista.

Os modernistas cariocas não tiveram acesso às altas esferas do poder, constituindo um grupo marginal frente, sobretudo, às academias que norteavam os debates na capital federal. Tal condição fez com que este grupo também optasse por não se constituir em movimento e abraçar o espaço marginal das ruas e da boêmia. Por outro lado, em São Paulo, os modernistas foram apoiados pela aristocracia cafeeira, sendo que muitos eram oriundos deste grupo social. Recife, por sua vez, ficou atada ao regionalismo, a outra face da renovação cultural que ficou numa posição de divergência em relação, principalmente, à Semana de 22. Seu principal líder, Gilberto Freyre, resgatou o passado do Nordeste em oposição à ânsia futurista de São Paulo. Essa soma de conjunturas diversas, na base do Modernismo brasileiro, propiciou uma maior visibilidade, na memória histórica, à Semana de Arte Moderna de 1922 e, ao mesmo tempo, ofuscou as memórias de outras práticas modernistas. 


\section{Notas}

1 Grupo de intelectuais mineiros que se reuniam na Rua da Bahia, em Belo Horizonte, nos anos de 1920, em torno da publicação A Revista. Dentre outros, destacaram-se Carlos Drummond de Andrade, Pedro Nava, João Alphonsus e Gustavo Capanema. (BOMENY, 1994)

2 De que podemos citar como exemplo a luta denominada pela historiografia como Movimento Tenentista, que expressa os ideais das classes médias urbanas. (FAUSTO, 1995)

\section{Referências}

ALMEIDA, José Mauricio Gomes de. Regionalismo e modernismo: as duas faces da renovação cultural dos anos 20. In: KOSMINSKY, Ethel Volfzon; LÉPINE, Claude; PEIXOTO, F. A. (Org.). Gilberto Freyre em quatro tempos. Bauru: Edusc, 2003.

BATALHA, Claudio Henrique M. Formação da classe operária e projetos de identidade coletiva. In: FERREIRA, Jorge; DELGADO, Lucilia de Almeida Neves (Org.). O Brasil Republicano I: o tempo do liberalismo excludente. Rio de Janeiro: Civilização Brasileira, 2003.

BERRIEL, Carlos Eduardo Ornelas. Tietê, Tejo, Sena: a obra de Paulo Prado. Campinas: Papirus, 2000.

BOMENY, Helena. Guardiães da Razão - modernistas mineiros. Rio de Janeiro: Editora UFRJ, 1994.

CANDIDO, Antonio. Literatura e sociedade. Rio de Janeiro: Ouro Sobre Azul, 2010.

CARVALHO, José Murilo de. Pontos e bordados: escritos de história e política. Belo Horizonte: Editora da UFMG, 1998.

DIMAS, Antônio. Um manifesto guloso. In: KOSMINSKY, Ethel Volfzon; LÉPINE, Claude; PEIXOTO, F. A. (Org.). Gilberto Freyre em quatro tempos. Bauru: Edusc, 2003.

DOMINGUES, José Maurício. A dialética da modernização conservadora e a nova história do Brasil. Dados - Revista de Ciências Sociais, Rio de Janeiro, v. 45, n. 03, 2002. ps. 459-482.

FAUSTO, Boris. A Revolução de 1930. São Paulo: Editora Brasiliense, 1995.

FERNANDES, Florestan. A revolução burguesa no Brasil - Ensaio de interpretação sociológica. Rio de Janeiro: Zahar Editores, 1976.

GOMES, Angela de Castro. Essa gente do Rio. . Modernismo e nacionalismo. Rio de Janeiro: Fundação Getulio Vargas, 1999. 
MOURA, Esmeralda Blanco Bolsonaro. Um sólido anzol de aço: Estado e ação operária na República Velha. Revista da ADUSP. São Paulo, jun.1997.

SEVCENKO, Nicolau. Literatura como missão: tensões sociais e criação cultural na Primeira República. São Paulo: Companhia das Letras, 1983.

Orfeu extático na metrópole: São Paulo, sociedade e cultura nos frementes anos 20. São Paulo: Companhia das Letras, 1992.

SÜSSEKIND, Flora. Cinematógrafo de letras - Literatura, técnica e modernização no Brasil. São Paulo: Companhia das Letras, 2006.

VELLOSO, Monica Pimenta. Modernismo no Rio de Janeiro. Rio de Janeiro: Fundação Getulio Vargas, 1996.

recebido em 21 out. 2012 / aprovado em 20 nov. 2012

Para referenciar este texto:

MENEZES, J. L. S. Modernismo brasileiro: muito além da Semana de Arte Moderna de 1922. Dialogia, São Paulo, n. 16, p. 167-184, 2012. 